\title{
Persepsi guru prasekolah kebangsaan terhadap program pembangunan profesional guru
}

\section{National preschool teacher's perception towards professional development program}

\author{
Zuriani Hanim Zaini ${ }^{1}$, \& Mahaliza Mansor ${ }^{2}$ \\ Fakulti Pengurusan dan Ekonomi, Universiti Pendidikan Sultan Idris, \\ Tanjong Malim, Perak, Malaysia ${ }^{1,2}$ \\ zurianihanim@gmail.com¹, mahaliza@fpe.edu.my² \\ DOI: https://doi.org/10.37134/saecj.vol8.no1.4.2019
}

Received: 03 April 2019; Accepted: 25 May 2019; Published: 21 June 2019

\begin{abstract}
ABSTRAK
PPPM 2013-2025 telah digubal bagi memastikan keberkesanan transformasi sistem pendidikan dan bermatlamat untuk meningkatkan kualiti dan sokongan guru serta pemimpin dalam organisasi pendidikan. Pembangunan profesionalisme secara umumnya merupakan satu usaha untuk memberikan pengalaman secara formal seperti menghadiri bengkel dan latihan yang khusus untuk meningkatkan kompetensi guru. Sehubungan itu, kajian ini dijalankan untuk mengenal pasti persepsi guru prasekolah terhadap tahap perancangan aktiviti pembangunan profesional guru yang telah mereka jalani. Kajian ini merupakan satu kajian kuantitatif berbentuk tinjauan yang menggunakan soal selidik sebagai intrumen kajian bagi mendapatkan persepsi guru prasekolah terhadap program pembangunan profesional. Kajian ini melibatkan seramai 260 orang sampel yang terdiri daripada guru prasekolah kebangsaan di Perak. Dapatan kajian menunjukkan persepi guru prasekolah terhadap program pembangunan profesional guru berada pada tahap yang tinggi. Ini menunjukkan program pembangunan profesional guru yang dilaksanakan mendapat persepsi yang baik daripada guru prasekolah.
\end{abstract}

Kata kunci: guru prasekolah, perancangan pembangunan profesional

\begin{abstract}
PPPM 2013-2025 has been enacted to ensure the effectiveness of education system transformation and aims to improve the quality and support of teachers and leaders in educational organizations. Professional development is generally an effort to provide a formal experience such as attending special workshops and exercises to improve teacher competence. In this regard, this study was conducted to identify the perceptions of preschool teachers on the level of planning of the professional development activities of the teachers. This study is a quantitative study in the form of surveys that uses questionnaires as a study instrument to obtain the perception of preschool teachers on professional development programs. This study is a small-scale study and covers only 260 samples comprising national preschool teachers in Perak. The findings show that preschool teachers' attitudes towards the professional development program are at a high level. It shows the professional development program of teachers undertaken to receive good perceptions from preschool teachers.
\end{abstract}

Keywords: preschool teachers, professional development planning 


\section{PENGENALAN}

Menjelang gelombang ketiga pelaksanaan Pelan Pembangunan Pendidikan Malaysia (PPPM, 20132025), kementerian berhasrat untuk mewujudkan budaya kecemerlangan profesionalisme teladan rakan setugas, iaitu guru membimbing di antara satu sama lain serta saling memberi inspirasi, berkongsi tentang amalan terbaik dan memastikan rakan setugas mengamalkan nilai kebertanggungjawaban untuk memenuhi standard profesional. Pendekatan Pembangunan Profesionalisme Berterusan (PPB) memberi keutamaan kepada inisiatif kendiri dan bukan bergantung kepada Kementerian Pendidikan Malaysia (KPM) atau sekolah semata-mata. Pelan Pembangunan Profesionalisme Berterusan (PPPB) telah mula diperkenalkan pada tahun 2013 sebagai melengkapi usaha pembangunan profesional guru dan pemimpin sekolah. PPPB bertujuan meningkatkan kualiti guru dan pemimpin sekolah dalam memperkasakan profesion perguruan yang menjadi faktor keberhasilan murid.

Pembangunan profesionalisme secara umumnya merupakan satu usaha untuk memberikan pengalaman secara formal seperti menghadiri bengkel dan latihan yang khusus untuk meningkatkan kompetensi guru. Amalan dalam bilik darjah yang berupaya memberikan impak kepada pembelajaran murid amat bergantung kepada tingkah laku guru (Fullan \& Miles, 1992).

National Association for the Education of Young Children (NAEYC) mendefinisikan golongan profesional dalam bidang pendidikan awal kanak-kanak (PAKK) adalah individu yang menyediakan perkhidmatan kepada kanak-kanak berumur (dari lahir hingga berumur lapan tahun) dan keluarga mereka serta sesiapa yang mentadbir program ini di mana individu tersebut bekerja. NAEYC (2007) turut menggariskan standard yang patut dipatuhi oleh guru dalam profesion pendidikan awal kanakkanak dan guru juga perlu memahami pengetahuan yang khusus untuk menjadi pendidik yang efektif dalam bidang ini. Oleh itu, pembangunan profesional guru PAKK wajar diberikan secara berterusan bagi memastikan keberkesanan pengajaran guru dengan berbekalkan kemahiran dan pengetahuan yang mencukupi seiring dengan perubahan dalam dasar dan sistem pendidikan (Azahari \& Mansor, 2018).

Pembangunan profesional berterusan memberi penekanan terhadap kesinambungan latihan praperkhidmatan dan dalam perkhidmatan guru perlu berfokuskan kepada pembelajaran profesional guru dan ketua sekolah dengan konteks yang berbeza serta pada masa yang berbeza (Stevenson, Hedberg, \& Howe, 2016). Oleh itu, peranan pihak pengurusan sekolah adalah penting untuk meningkatkan penghayatan dan pemahaman guru untuk melaksanakan Kurikulum Standard Prasekolah Kebangsaan (KSPK) 2017 dengan lebih baik.

Tambahan lagi, program pembangunan profesional guru selalunya hanya berfokuskan kepada latihan dalam perkhidmatan melalui kursus dan bengkel secara formal dan menyebabkan kurangnya komitmen dan penglibatan guru. Walton, Nel, Muller, \& Lebeloane (2014) dalam kajiannya yang dibuat terhadap guru PAKK menunjukkan usaha untuk mengimplimentasikan program pembangunan profesional berterusan tidak mencukupi keperluan pendidik secara individu atau dalam konteks institusi. Malah, kajian Silva dan Herdeiro (2015) menunjukkan latihan dan pembangunan guru kurang diberi penekanan disebabkan oleh pelbagai faktor seperti kekurangan peruntukan, kesuntukan masa, beban kerja, dan karenah birokrasi.

Kewujudan pendidikan prasekolah adalah bertujuan menyediakan asas yang kukuh kepada kanak-kanak sebelum melangkah ke alam persekolahan formal di sekolah rendah. Pembangunan kurikulum yang komprehensif adalah penting untuk menjadi pemandu kearah mencapai matlamat pendidikan. KSPK berhasrat untuk memperkembangkan potensi murid empat hingga enam tahun secara menyeluruh dan bersepadu dalam aspek jasmani, emosi, intelek dan sosial melalui persekitaran pembelajaran yang selamat, menyuburkan dengan aktiviti pembelajaran yang menyeronokkan, kreatif dan bermakna (Kementerian Pendidikan Malaysia, 2017). Bagi merealisasikan matlamat ini, guru memainkan peranan penting dalam memberi pendidikan yang bermakna kepada kanak-kanak. Tanpa komitmen dan usaha yang berterusan daripada guru, usaha ini pasti tidak akan membuahkan hasil. 
Golongan profesional dalam bidang PAKK perlu menguasai standard pendidikan dan menjalani latihan untuk persediaan dari segi pengetahuan dan kemahiran tertentu yang diperlukan untuk melaksanakan peranan sebagai pendidik awal kanak-kanak (Brown, Cheddie, Horry, \& Monk, 2017). Menurut Caulfield (1997), untuk menjadi profesional dalam bidang PAKK memerlukan satu bentuk kemahiran yang dapat meningkatkan kualiti pengasuhan dan interaksi antara penjaga dengan kanak-kanak serta keluarga mereka. Malah, aspek profesionalisme inilah yang membezakan bidang PAKK dengan bidang yang lain.

Menurut NAEYC (2007), salah satu konsep penting dalam perkembangan pendidikan kanak-kanak adalah kurikulum yang bersesuian dengan fitrah dan perkembangan kanak-kanak yang suka bermain. NAEYC (2007) turut menegaskan pengajaran dan pembelajaran dalam PAKK perlu mengikut amalan bersesuaian dengan perkembangan kanak-kanak atau Developmentally Appropriate Practice (DAP) supaya kanak-kanak dapat belajar mengikut keperluan dan kesesuaian perkembangan. Menurut Masnan (2014), sekiranya guru tidak memiliki dan menguasai pengetahuan pedagogi dalam konteks pendidikan prasekolah, maka PdPc yang dilaksanakan akan berbentuk formal dan lebih banyak berfokus kepada guru, sedangkan matlamat pendidikan prasekolah adalah kanak-kanak bebas meneroka untuk belajar sesuatu.

Pemimpin dan setiap warga sekolah perlu berkongsi tanggungjawab terhadap pembangunan profesional guru kerana petunjuk utama bagi sekolah berkesan di Malaysia adalah berdasarkan pengurusan organisasi, hala tuju kepimpinan, kemenjadian murid dan pengurusan program pendidikan (Jemaah Nazir Sekolah, 2003). Tambahan pula, pembangunan profesional guru prasekolah memerlukan pendekatan yang spesifik dan bersesuaian dengan perkembangan sosial dan emosi kanak-kanak. Ini kerana walaupun mempunyai kurikulum yang komprehensif, tetapi meletakkan jangkaan yang tinggi kepada pendidik tanpa memberikan pembangunan profesional guru yang menepati standard kurikulum sebenar akan memberi kesan terhadap amalan pengajaran guru dan keberhasilan murid kerana pelaksanaan kurikulum yang komprehensif memerlukan tahap pengetahuan dan kemahiran guru yang tinggi pada peringkat awal (Neuman \& Kamil, 2010).

Penambahbaikan KSPK (Semakan 2017) telah dibuat bagi meningkatkan kualiti kurikulum yang lebih holistik, mengikut keperluan semasa serta ada kesinambungan dengan Kurikulum Standard Sekolah Rendah (KSSR). Namun demikian, perubahan ini tidak mencukupi sekiranya tiada implimentasi dalam pembelajaran dan pemudahcaraan (PdPc) guru. Kajian Chee, Nor, Othman, \& Rahman (2015) mendapati setelah lima tahun pelaksanaan KSPK (Kementerian Pendidikan Malaysia, 2010), masih terdapat sebilangan guru yang gagal menyampaikan isi kandungan pengajaran dan pedagogi seperti yang disarankan dalam KSPK. Seterusnya, Kassim dan Hanim (2015) menjelaskan terdapat tiga perkara utama yang menjadi permasalahan yang ketara dihadapi oleh golongan pendidik, iaitu kandungan kurikulum yang kurang tepat dan jelas, kemahiran pedagogi atau kaedah penyampaian pengajaran yang kurang dikuasai dan kekurangan sumber pengajaran. Sehubungan itu, kajian ini perlu dilakukan untuk mengkaji persepsi guru prasekolah terhadap program pembangunan profesional yang telah mereka ikuti sepanjang dalam perkhidmatan. Objektif kajian ini dijalankan adalah untuk mengenal pasti persepsi guru prasekolah terhadap tahap perancangan aktiviti pembangunan profesional guru.

\section{METODOLOGI}

Kajian ini berbentuk kuantitatif yang menggunakan kaedah tinjauan deskriptif bagi mendapatkan pandangan guru prasekolah terhadap program pembangunan profesional. Kaedah kuantitatif membolehkan data dikumpulkan dan dianalisis untuk menghasilkan maklumat dan pengetahuan tentang pendapat, sikap dan amalan (Gall, Gall, \& Borg, 2007).

Kajian ini melibatkan seramai 260 orang sampel yang terdiri daripada guru prasekolah kebangsaan di Perak. Penentuan saiz sampel kajian ini ditentukan mengikut jadual penentuan saiz 
sampel Krejcie dan Morgan (1970). Populasi responden kajian ialah 808 orang guru prasekolah di Perak, maka hanya 260 orang guru prasekolah sahaja yang diperlukan sebagai sampel kajian ini.

Instrumen kajian ini menggunakan soal selidik yang diaptasi daripada Model RPTIM (Wood, McQuirrie, \& Thompson, 1981) dalam aspek tahap perancangan program pembangunan profesional guru. Model RPTIM ini merupakan satu set panduan untuk menentukan amalan yang patut digunakan untuk membuat reka bentuk program yang efektif untuk pendidik profesional yang sedang dalam perkhidmatan. Selain itu, instrumen ini telah diubah suai dalam aspek struktur ayat dan penambahan terma "prasekolah" supaya bersesuaian dengan situasi responden kajian ini. Kaedah skala lima likert telah digunakan sebagai pilihan jawapan responden kajian bagi mengenal pasti tahap pembangunan profesional guru prasekolah. Skala lima likert ini juga digunakan untuk memudahkan pengkaji bagi mengenal pasti pandangan dan penilaian responden terhadap item yang dirasakan sesuai. Jadual 1 berikut menunjukkan skor penilaian skala lima likert yang digunakan;

Jadual 1: Skor Skala Lima Likert

\begin{tabular}{lc}
\hline Pernyataan & Skor \\
\hline Sangat Tidak Setuju & 1 \\
Tidak Setuju & 2 \\
Kurang Pasti & 3 \\
Setuju & 4 \\
Sangat Setuju & 5 \\
\hline
\end{tabular}

Seterusnya, pengkaji menganalisis data dengan menggunakan perisian SPSS untuk mendapatkan nilai min bagi setiap item. Bagi kajian ini, rujukan skor min yang dikemukakan oleh Pallant (2007) telah digunakan seperti dalam Jadual 2 berikut:

Jadual 2: Tafsiran Skor Min

\begin{tabular}{cc}
\hline Tahap & Tafsiran Skor Min \\
\hline Tinggi & $3.68-5.00$ \\
Sederhana & $2.34-3.67$ \\
Rendah & $1.00-2.33$ \\
\hline
\end{tabular}

\section{DAPATAN KAJIAN}

Dapatan kajian ini merujuk kepada nilai min bagi tahap perancangan pembangunan profesional guru yang merangkumi lima item seperti dalam Jadual 3 berikut:

Jadual 3: Tahap Perancangan Pembangunan Profesional Guru

\begin{tabular}{llccc} 
Bil & Item & $\begin{array}{c}\text { Nilai } \\
\text { Min }\end{array}$ & $\begin{array}{c}\text { Sisihan } \\
\text { Piawai }\end{array}$ & Tahap \\
\hline 1. & $\begin{array}{l}\text { Perancangan aktiviti pembangunan profesional yang dijalankan } \\
\text { adalah berdasarkan kepada keperluan saya sebagai guru } \\
\text { prasekolah }\end{array}$ & 3.83 & .789 & Tinggi \\
2. & $\begin{array}{l}\text { Objektif aktiviti yang khusus ditulis dengan jelas semasa saya } \\
\text { menghadiri program pembangunan profesional. }\end{array}$ & 4.06 & .725 & Tinggi \\
3. & $\begin{array}{l}\text { Perancangan objektif aktiviti pembangunan profesional guru } \\
\text { merangkumi objektif pembaharuan sikap guru. }\end{array}$ & 4.18 & .673 & Tinggi \\
4. & $\begin{array}{l}\text { Perancangan objektif aktiviti pembangunan profesional guru } \\
\text { merangkumi objektif untuk meningkatkan pengetahuan guru. }\end{array}$ & 4.12 & .699 & Tinggi \\
\end{tabular}


Perancangan objektif aktiviti pembangunan profesional guru merangkumi objektif untuk meningkatkan kemahiran guru.

Tahap Perancangan Program Pembangunan Profesional Guru
4.08

4.05
.723

.723
Tinggi

Tinggi

Jadual 3 menunjukkan nilai min bagi setiap item berkaitan tahap perancangan pembangunan profesional guru. Dapatan kajian menunjukkan tahap perancangan pembangunan profesional guru mengikut persepsi guru prasekolah berada pada tahap yang tinggi $(\mathrm{M}=4.05 ; \mathrm{SP}=.723)$. Nilai min yang paling tinggi ialah item ketiga $(\mathrm{M}=4.18 ; \mathrm{SP}=.673)$ yang menunjukkan objektif pembaharuan sikap guru dalam perancangan program pembangunan profesional berada pada tahap tinggi. Manakala, nilai min yang paling rendah ialah item pertama $(\mathrm{M}=3.83 ; \mathrm{SP}=.789)$ yang menunjukkan perancangan aktiviti pembangunan profesional yang dijalankan memenuhi keperluan guru prasekolah juga berada pada tahap tinggi.

\section{PERBINCANGAN DAN IMPLIKASI KAJIAN}

Kajian ini mendapati tahap perancangan program pembangunan profesional guru adalah tinggi yang menunjukkan program pembangunan profesional guru yang dilaksanakan mendapat persepsi yang baik daripada guru prasekolah. Malah, perancangan pembangunan profesional guru memenuhi keperluan guru prasekolah. Seterusnya, dapatan kajian ini juga menunjukkan guru prasekolah berpuas hati dengan perancangan pembangunan profesional yang mereka jalani memandangkan objektif yang khusus dalam program pembangunan profesional guru ditulis dengan jelas dan merangkumi objektif untuk meningkatkan pembaharuan sikap, pengetahuan dan kemahiran guru.

Dapatan kajian ini bersesuaian dengan kajian yang dilakukan terhadap guru di sekolah berprestasi tinggi (Ghani, Adnan, Hussin, Radzi, Ahmad, \& Elham, 2017) yang menunjukkan tahap keberkesanan program pembangunan profesional guru adalah tinggi di kedua-dua zon iaitu di zon tengah dan di zon selatan Malaysia. Dalam kajian yang dijalankan di sekolah berprestasi tinggi dan berprestasi rendah turut mendapati tahap keberkesanan pelaksanaan program perkembangan profesionalisme guru di sekolah terbabit adalah tinggi dan sangat memuaskan (Ghani \& Adnan, 2016). Ini kerana guru mengakui pelaksanaan program pembangunan profesional guru dapat meningkatkan pengetahuan, kemahiran dan sikap profesional guru. Namun demikian, dapatan kajian ini boleh dipengaruhi oleh faktor-faktor kecendurungan sampel kajian untuk memberikan jawapan yang baik tanpa mengira perasaan sebenar mereka kerana mengaggap keperluan terhadap tanggapan sosial supaya boleh diterima dan sesuai dengan budaya (Podasakoff, Mckenzie, Lee \& Podsakoff, 2003). Oleh itu, bagi mengurangkan respon yang dipengaruhi oleh tanggapan sosial (social desirable response), responden perlu diingatkan bahawa tiada jawapan yang betul atau salah pada setiap bahagian dalam soal selidik (Podsakoff \& Organ, 1986).

Walau bagaimanapun, kajian Nor, Rahman, Nor, \& Razak (2017) yang telah dilakukan secara temu bual terhadap enam orang guru besar di sekolah berprestasi tinggi berpendapat perkembangan profesionalisme guru memberi kesan kepada kemahiran serta kompetensi guru dalam pengajaran, maka secara tidak langsung pengawalan masa pengajaran guru di dalam kelas dapat dioptimumkan. Dapatan kajian ini juga menunjukkan persamaan dengan kajian yang dilakukan oleh Chang, Chen, \& Chou (2017) di Taipei, Taiwan. Gaya kepimpinan perubahan yang ditunjukkan oleh pengetua boleh memberi impak yang besar kepada pembangunan profesional guru dalam aspek kesanggupan penyertaan dan keberkesanan penyertaan guru ke program pembangunan profesional yang dianjurkan. Kajian tersebut juga mengenal pasti persepsi guru turut dipengaruhi oleh jantina, pengalaman mengajar dan saiz skala sekolah.

Oleh yang demikian, pembelajaran tidak sepatutnya terhenti setakat di unversiti sahaja. Blank (2014) menyatakan proses pembelajaran guru bukan hanya terhenti setakat pendidikan dalam peringkat ijazah, tetapi perlu berterusan sehingga menghadiri program berkaitan peningkatan profesionalisme diri apabila mereka telah berkhidmat di sekolah. Pembelajaran yang bereterusan semasa dalam perkhidmatan adalah untuk meningkatkan dan membekalkan ilmu pengetahuan serta kemahiran yang 
mencukupi kepada guru supaya seiring dengan perubahan dalam dasar dan sistem pendidikan semasa yang ingin mentranformasi pendidikan menjadi lebih baik dan bermutu sejajar dengan kehendak global (Mansor, Norlia, \& Jamal 2014; KPM, 2013).

Walau bagaimanapun terdapat beberapa kelemahan dalam menjalankan kajian ini, antaranya ialah responden hanya terdiri daripada guru prasekolah kebangsaan di Perak. Oleh itu, dapatan kajian ini tidak dapat digeneralisasikan kepada semua populasi dan tempat. Justeru, kajian yang akan datang patut dilanjutkan dengan jumlah data yang lebih optimum. Selain itu, kajian yang lebih terperinci mengenai keberkesanan program pembangunan profesional perlu dijalankan supaya semakin banyak model dan instrumen yang boleh digunakan untuk menilai standard dan kualiti program pembangunan profesional guru secara berterusan.

\section{KESIMPULAN}

Pembangunan profesional guru merupakan medium yang sangat penting bagi membantu guru untuk meningkatkan kemahiran dan pengetahuan, di samping pemimpin yang memberi sokongan dalam membentuk keyakinan guru untuk menjadi lebih berjaya dalam profesion ini. Semoga dapatan kajian ini boleh menjadi batu loncatan kepada penambahbaikan program pembangunan profesional guru prasekolah di Malaysia pada masa akan datang.

\section{RUJUKAN}

Ali, A., \& Mahamod, Z. (2017). Analisis keperluan terhadap pengguna sasaran modul pendekatan berasaskan bermain bagi pengajaran dan pembelajaran kemahiran bahasa kanak-kanak prasekolah. JuKu: Jurnal Kurikulum \& Pengajaran Asia Pasifik, 3(1), 1-8.

Azahari, W. A. F. W., \& Mansor, M. (2018). Pengaruh amalan pembelajaran profesional terhadap kepimpinan guru-guru kolej vokasional di Perak. Management Research Journal, 7, 32-43.

Blank, R. K. (2010). A better way to measure: New survey tool gives educators a clear picture of professional learning's impact. The Learning Professional, 31(4), 56.

Brown, C. S., Cheddie, T. N., Horry, L. F., \& Monk, J. E. (2017). Training to be an early childhood professional: teacher candidates ' perceptions about their education and training, 5(6), 177-186.

Caulfield, R. (1997). Professionalism in early care and education. Early Childhood Education Journal, 24(4), 261-263.

Chang, D. F., Chen, S. N., \& Chou, W. C. (2017). Investigating the major effect of principal's change leadership on school teachers' professional development. IAFOR Journal of Education, 5(3), 139-154.

Chee, J., Nor, M. M., Othman, A. J., \& Rahman, M. N. A. (2018). Isu Pengetahuan kandungan, pedagogi dan teknologi dalam kalangan guru prasekolah. JuKu: Jurnal Kurikulum \& Pengajaran Asia Pasifik, 6(1), 721.

Fullan, M.G. (1992). Getting reform right: What works and what doesn't. Phi Delta Kappa, 73(10), 744-52.

Gall, M., Gall, \& Borg, W. (2007). Educational research. MA: Pearson.

Ghani, M. F. A., \& Adnan, A. K. (2016). Model program perkembangan profesionalisme guru Malaysia: Satu kajian analisis keperluan di sekolah berprestasi tinggi dan sekolah berprestasi rendah. JuPiDi: Jurnal Kepimpinan Pendidikan, 2(2), 1-16.

Ghani, M. F. A., Adnan, A. K., Hussin, Z., Radzi, N. M., Ahmad, A. M., \& Elham, F. (2017). Program pembangunan profesionalisme guru sekolah berprestasi tinggi. Jupidi: Jurnal Kepimpinan Pendidikan, 3(3), 76-103.

Guskey, T. (2015). Evaluating professional development. Thousand Oaks, CA: Corwin Press.

Kementerian Pendidikan Malaysia. (2010). Kurikulum Prasekolah Kebangsaan. Putrajaya: Bahagian Pembangunan Kurikulum, Kementerian Pendidikan Malaysia.

Kementerian Pendidikan Malaysia. (2017). Kurikulum Standard Prasekolah Kebangsaan (semakan 2017). Putrajaya: Bahagian Pembangunan Kurikulum, Kementerian Pendidikan Malaysia.

Kementerian Pendidikan Malaysia. (2013). Pelan Pembangunan Pendidikan Malaysia 2013-2025. Putrajaya, Malaysia: Kementerian Pendidikan Malaysia.

Krejcie, R. V., \& Morgan, D. W. (1970). Determining sample size for research activities. Educational and psychological measurement, 30(3), 607-610. 
Mansor, M., Norlia Mat Norwani, \& Jamal@Nordin Yunus. (2014). Hubungan antara model-model pembelajaran profesional terhadap amalan guru sekolah menengah harian di Malaysia. Jurnal Pendidikan Bitara UPSI, $6(5)$.

Masnan, A. H. (2014). Amalan pedagogi guru prasekolah permulaan (Doctoral dissertation, Universiti Pendidikan Sultan Idris).

National Association for the Education of Young Children (2007). NAEYC early childhood program standard and accreditation criteria: The mark of quality in early childhood education. Washington DC: Author.

Neuman, S. B., \& Kamil, M. L. (Eds.). (2010). Preparing teachers for the early childhood classroom: Proven models and key principles. Paul H. Brookes.

Nor, M. M., Rahman, M. N. A., Nor, N. M., \& Razak, A. Z. A. (2017). Amalan kepimpinan pengajaran untuk penambahbaikan sekolah: Retrospeksi guru besar sekolah berprestasi tinggi. JuPiDi: Jurnal Kepimpinan Pendidikan, 3(3), 44-53.

Pallant, J. (2007). SPSS survival manual: A step-by-step guide to data analysis using SPSS for windows (version 10). Buckinham, UK: Open University Press

Podsakoff, P. M., \& Organ, D. W. (1986). Self-reports in organizational research: Problems and prospects. Journal of Management, 12(4), 531-544.

Podsakoff, P. M., MacKenzie, S. B., Lee, J. Y., \& Podsakoff, N. P. (2003). Common method biases in behavioral research: A critical review of the literature and recommended remedies. Journal of Applied Psychology, 88(5), 879-903.

Silva, A. M., \& Herdeiro, R. (2015). The work, perceptions and professional development of teachers, Teaching and Teacher Education, 25(2).

Stevenson, M., Hedberg, J. G., \& Howe, C. (2016). Professional development in education leading learning: The role of school leaders in supporting continuous professional development. Professional Development in Education, 5257, 1-18.

Walton, E., Nel, N. M., Muller, H., \& Lebeloane, O. (2014). You can train us until we are blue in our faces, we are still going to struggle: Teacher professional learning in a full-service school. Education as change, 18(2), 319-333.

Wood, F. H., McQuirrie, F., \& Thompson, S. R. (1981). Practitioners and professors agree on effective staff development practices. Educational Leadership. 